\title{
Persistent luminescence in nitride and oxynitride phosphors: a review
}

Philippe F. Smet, Jonas Botterman, Koen Van den Eeckhout, Katleen Korthout, Dirk Poelman LumiLab, Department of Solid State Sciences, Ghent University, Krijgslaan 281-S1, 9000 Gent, Belgium.

Center for Nano- and Biophotonics (NB Photonics), Ghent University, Belgium.

This paper was published as Optical Materials 36 (2014) 1913-1919

This version is the unedited, accepted version after peer review.

\author{
The edited version can be found at \\ http://dx.doi.org/10.1016/i.optmat.2014.05.026
}

Optical Materials 36 (2014) 1913-1919

Persistent luminescence in nitride and oxynitride phosphors: A review

Philippe F. Smet*, Jonas Botterman, Koen Van den Eeckhout, Katleen Korthout, Dirk Poelman

LumiLab, Department of Solid State Sciences, Ghent University, Krijgslaan 281-S1, 9000 Ghent, Belgium Center for Nano- and Biophotonics (NB Photonics), Ghent University, Belgium

\section{A R T I C L E I N F O}

\section{Article history:}

Available online 23 June 2014

\section{Keywords:}

Persistent luminescence

Rare earth

Nitrides

Oxynitrides

Thermoluminescence

Europium

\section{A B S T R A C T}

The research field of persistent luminescence has experienced a strong growth in the past two decades, with a steady development of new materials and applications. Here we give an overview of the recent progress in a specific class of host materials, namely oxynitride and nitride persistent phosphors. These are interesting hosts to explore because of their unique characteristics, such as chemical stability and tunability of the emission over the entire visible range upon doping with divalent europium. To yield persistent luminescence however, co-dopants have to be added or the synthesis conditions have to be adjusted. Specific materials, such as $\mathrm{Ca}_{2} \mathrm{Si}_{5} \mathrm{~N}_{8}$ :Eu,Tm and $\mathrm{BaSi}_{2} \mathrm{O}_{2} \mathrm{~N}_{2}: \mathrm{Eu}$, are highlighted and their properties are put into the context of emerging applications such as in vivo imaging and pressure sensing via mechanoluminescence. Finally, directions for future research are given.

(c) 2014 Elsevier B.V. All rights reserved. 


\title{
Persistent luminescence in nitride and oxynitride phosphors: a review
}

\author{
Philippe F. Smet, Jonas Botterman, Koen Van den Eeckhout, Katleen Korthout, Dirk Poelman \\ LumiLab, Department of Solid State Sciences, Ghent University, Krijgslaan 281-S1, 9000 Gent, Belgium.
}

Center for Nano- and Biophotonics (NB Photonics), Ghent University, Belgium.

\begin{abstract}
The research field of persistent luminescence has experienced a strong growth in the past two decades, with a steady development of new materials and applications. Here we give an overview of the recent progress in a specific class of host materials, namely oxynitride and nitride persistent phosphors. These are interesting hosts to explore because of their unique characteristics, such as chemical stability and tunability of the emission over the entire visible range upon doping with divalent europium. To yield persistent luminescence however, codopants have to be added or the synthesis conditions have to be adjusted. Specific materials, such as $\mathrm{Ca}_{2} \mathrm{Si}_{5} \mathrm{~N}_{8}: \mathrm{Eu}, \mathrm{Tm}$ and $\mathrm{BaSi}_{2} \mathrm{O}_{2} \mathrm{~N}_{2}: \mathrm{Eu}$, are highlighted and their properties are put into the context of emerging applications such as in vivo imaging and pressure sensing via mechanoluminescence. Finally, directions for future research are given.
\end{abstract}

\section{Introduction.}

Persistent luminescence is a specific type of photoluminescence for which the emission is delayed by minutes, hours or even days after the excitation has ended. This process is most often temperature dependent and is also called afterglow or long-lasting phosphorescence (LLP) $[1,2]$.

Although the first persistent phosphor was already scientifically described four centuries ago [3], dedicated research into this class of materials only geared up after the discovery of strontium aluminate doped with europium and dysprosium $\left(\mathrm{SrAl}_{2} \mathrm{O}_{4}: \mathrm{Eu}, \mathrm{Dy}\right)$, now twenty years ago $[4,5]$. Since then, many new phosphor materials have been reported $[6,7]$, which can be roughly divided into two groups. The first group is based on the use of divalent europium as luminescence center, often with other rare earth ions as co-dopants. The most studied materials in this group are $\mathrm{CaAl}_{2} \mathrm{O}_{4}: \mathrm{Eu}, \mathrm{Nd}$ $[8,9], \mathrm{Sr}_{2} \mathrm{MgSi}_{2} \mathrm{O}_{7}: \mathrm{Eu}, \mathrm{Dy}[10], \mathrm{SrAl}_{2} \mathrm{O}_{4}: \mathrm{Eu}, \mathrm{Dy}[5,11]$ and $\mathrm{Sr}_{4} \mathrm{Al}_{14} \mathrm{O}_{25}: \mathrm{Eu}, \mathrm{Dy}$ [12]. An extensive overview is given in the review by Van den Eeckhout et al. [7]. The second group contains non-rare earth ions (such as $\mathrm{Mn}^{2+}$ [13] or $\mathrm{Cr}^{3+}[14-16]$ ) or other rare earth ions (such as $\mathrm{Eu}^{3+}$, $\mathrm{Dy}^{3+}$ and $\mathrm{Tb}^{3+}$ ) as luminescence centers. A recent overview on the members in this second group can be found in [6].

In general terms, the first step in the process of persistent luminescence is the liberation of charge carriers upon illumination at specific wavelengths. These are subsequently trapped at defects, which are intrinsically present in the material or which were intentionally introduced. By thermally assisted detrapping or quantum tunneling effects, the charges can then move to a recombination center to yield the delayed luminescence [17-19]. Several aspects of this trapping and detrapping process in persistent phosphors are still under debate, mainly on the (chemical) nature of the traps and the trapping/detrapping pathways [20,21]. Consequently, the optimization of persistent phosphors and the discovery of new ones is often still a matter of trial-and-error. 
Next to the efforts towards unravelling the mechanism behind persistent luminescence, there are two driving forces steering the research and development of persistent phosphors. First of all, there is an interest to extend the more traditional applications areas (such as emergency signage, watch dials toys and gadgets), by increasing the brightness and decay time. This would allow night-long emission with sufficient brightness, for instance for use as glow-in-the-dark roadmarks.

Secondly, the current gamut of emission colours is mainly limited to the blue and green part of the spectrum. The development of red emitting materials is required for extending the colour range of glow-in-the-dark signage used in emergency situations. The low eye sensitivity for red light, especially under low light conditions, puts strong demands on the brightness of these phosphors [22, 23]. Emission in the deep red part of the visible spectrum or in the near-infrared are desired for surveillance applications [24] and in vivo bio imaging [25, 26].

In this paper we give an overview of the present state-of-the-art for persistent luminescence in oxynitride and nitride hosts, and discuss their usefulness in the for the abovementioned applications. The discussed compounds are given in Table 1. For the afterglow duration, we take the convention of using the $0.32 \mathrm{mcd} / \mathrm{m}^{2}$ threshold, similar to the procedure used in industrial testing [27]. This threshold is about 100 times the visibility threshold of the dark adapted human eye.

Unfortunately, it appears that the afterglow duration is sometimes determined without making absolute intensity measurements but by observing the sample with the dark adapted human eye, until dropping below the visibility threshold. This duration is then matched with the $0.32 \mathrm{mcd} / \mathrm{m}^{2}$, which obviously compromises the objective comparison of different reports or different persistent phosphors. A complication is that the eye sensitivity curve shifts to shorter wavelengths for low light intensities, as encountered in the mesopic or scotopic range [23]. Therefore, absolute measurements (even in radiometric units in the case of long wavelength emission [24]) are advisable, preferably also with clear specifications of the excitation conditions (spectral distribution, duration and intensity).

\begin{tabular}{|c|c|c|c|c|c|c|}
\hline Material & Dopant(s) & $\begin{array}{l}\lambda_{\max } \\
(\mathrm{nm})\end{array}$ & $\begin{array}{c}\text { FWHM } \\
\text { (nm) }\end{array}$ & Excitability & $\begin{array}{l}\text { Afterglow } \\
\text { (s) }\end{array}$ & Ref \\
\hline \multirow{2}{*}{$\mathrm{Ca}_{2} \mathrm{Si}_{5} \mathrm{~N}_{8}$} & $\mathrm{Eu}$ & \multirow{2}{*}{615} & \multirow{2}{*}{92} & \multirow{2}{*}{+} & $150\left(^{*}\right)-1200(\mathrm{o})$ & \multirow{2}{*}{ [26-32] } \\
\hline & $\mathrm{Eu}, \mathrm{Tm}$ & & & & $2500\left(^{*}\right)-3600(0)$ & \\
\hline \multirow{2}{*}{$\mathrm{Sr}_{2} \mathrm{Si}_{5} \mathrm{~N}_{8}$} & $\mathrm{Eu}$ & \multirow{2}{*}{625} & \multirow{2}{*}{88} & \multirow{2}{*}{-} & $80-150\left(^{*}\right)$ & \multirow{2}{*}[27,33]{} \\
\hline & $\mathrm{Eu}, \mathrm{Tm}$ & & & & $190-600\left(^{*}\right)$ & \\
\hline $\mathrm{SrCaSi}_{5} \mathrm{~N}_{8}$ & $\mathrm{Eu}, \mathrm{Tm}$ & 647 & 120 & $?$ & $1800(*)$ & [34] \\
\hline $\mathrm{Ba}_{2} \mathrm{Si}_{5} \mathrm{~N}_{8}$ & $\mathrm{Eu}$ & 585 & 93 & $\mathrm{~T}$ & $400(*)$ & {$[27,31,35]$} \\
\hline g- $\mathrm{C}_{3} \mathrm{~N}_{4}$ & None & 553 & 175 & + & 4800 (o) & {$[36]$} \\
\hline $\mathrm{CaSi}_{2} \mathrm{O}_{2} \mathrm{~N}_{2}$ & $\mathrm{Eu}$ & 506 & 106 & - & $400(*)$ & [37] \\
\hline $\mathrm{SrSi}_{2} \mathrm{O}_{2} \mathrm{~N}_{2}$ & $\mathrm{Eu}$ & 539 & 76 & - & $6000(*)$ & {$[37,38]$} \\
\hline $\mathrm{BaSi}_{2} \mathrm{O}_{2} \mathrm{~N}_{2}$ & $\mathrm{Eu}$ & 498 & 32 & + & $2800(*)$ & {$[37,39-41]$} \\
\hline $\mathrm{BaAlSi}_{5} \mathrm{~N}_{7} \mathrm{O}_{2}$ & $\mathrm{Eu}$ & 515 & 125 & - & $2400(0)$ & [42] \\
\hline BCNO & None & 520 & 90 & + & 7200 (o) & [43] \\
\hline
\end{tabular}

Table 1. Key data for (oxy)nitrides showing persistent luminescence. $\lambda_{\max }$ is the wavelength of the afterglow emission peak, FWHM is the full width at half maximum. Excitability refers to the possibility to induce persistent luminescence by visible light (+: good; T: temperature dependent; -: poor; ?: not reported). Afterglow duration $\left(\left(^{*}\right)\right.$ to $0.32 \mathrm{mcd} / \mathrm{m}^{2}$; (o): observed by naked eye).

\section{Overview of nitride phosphors}


$\mathrm{Eu}^{2+}$ doped nitride phosphors are key to achieve low colour temperature, high colour rendering and high efficiency in phosphor-converted white LEDs [44, 45]. Although the combination of a blue pumping LED and a yellow YAG:Ce phosphor readily produces white light with high colour temperature, the emission lacks in the red part of the spectrum. To achieve lamps with colour temperature in the $3000 \mathrm{~K}$ range and a high colour rendering index, a second phosphor is required. The red phosphors should preferably have a relatively narrow emission band and a peak wavelength not higher than $625 \mathrm{~nm}$, otherwise the human eye is not sensitive enough for the emitted light and the efficiency of the LED is compromised [46]. When using $\mathrm{Eu}^{2+}$ as dopant ion, this can in general only be achieved in certain sulfide (e.g. $\mathrm{Ca}_{1-\mathrm{S}} \mathrm{Sr} \mathrm{S}_{\mathrm{S}} \mathrm{Eu}$ ) or nitride hosts $[47,48]$. The latter materials are commonly preferred, due to stability issues with sulfides [49] and a better thermal quenching behaviour. Several high performance nitride materials have been developed, such as $\mathrm{Sr}_{2} \mathrm{Si}_{5} \mathrm{~N}_{8}: \mathrm{Eu}$, $\mathrm{Ba}_{2} \mathrm{Si}_{5} \mathrm{~N}_{8}: \mathrm{Eu}, \mathrm{CaAlSiN}_{3}: \mathrm{Eu}$ and $\mathrm{SrAlSiN}_{3}: \mathrm{Eu}$ (including solid solutions to obtain spectrally optimized phosphors) [50-53]. The research on persistent phosphors has taken advantage of these developments, with the $\mathrm{M}_{2} \mathrm{Si}_{5} \mathrm{~N}_{8}$ :Eu compositions getting attention.

Miyamoto et al. and Van den Eeckhout et al. independently reported on the persistent luminescence in $\mathrm{Ca}_{2} \mathrm{Si}_{5} \mathrm{~N}_{8}$ :Eu and the influence of especially co-doping with $\mathrm{Tm}^{3+}$ to increase the afterglow intensity $[30,32]$. The afterglow duration of $\mathrm{Ca}_{2} \mathrm{Si}_{5} \mathrm{~N}_{8}$ :Eu without co-dopants was found to be only 150 s, taking $0.32 \mathrm{mcd} / \mathrm{m}^{2}$ as threshold. This was related to a thermoluminescence peak around $350 \mathrm{~K}$, albeit with low intensity due to a limited number of traps [31]. The afterglow duration increases to 2500s upon appropriate codoping with thulium [27]. The addition of thulium introduces new traps, which are observed in the thermoluminescence glow curves around 220K (which is of no use for afterglow at room temperature) and 350 to $375 \mathrm{~K}[30,32]$. Next to these glow peaks, a very shallow intrinsic trap is found in all $\mathrm{Ca}_{2} \mathrm{Si}_{5} \mathrm{~N}_{8}: \mathrm{Eu}, \mathrm{RE}$ phosphors, with release at $110 \mathrm{~K}$ in thermoluminescence [30, 32]. The addition of Dy or $\mathrm{Nd}$ to $\mathrm{Ca}_{2} \mathrm{Si}_{5} \mathrm{~N}_{8}$ :Eu does introduce additional traps, but these are too shallow to play a role at room temperature [30, 32]. The deeper trap observed at $350 \mathrm{~K}-375 \mathrm{~K}$ was related to isolated $\mathrm{Tm}^{3+}$ ions or to $\mathrm{Tm}^{3+}-\mathrm{Eu}^{2+}$ pairs at the $\mathrm{Ca}^{2+}$ site(s) [30]. It was observed that the concentrations of europium and thulium have to be fairly low (in the range from 0.5 to $1 \%$ substitution of $\mathrm{Ca}$ ) $[27,30]$. The persistent luminescence can be influenced by variations in the $\mathrm{Ca}: \mathrm{Si}$ stoichiometry, and by addition of Li $[27,28,30]$.

Maldiney et al. showed that $\mathrm{Ca}_{2} \mathrm{Si}_{5} \mathrm{~N}_{8}$ : Eu,Tm can effectively be used for in vivo imaging of small animals, by following the afterglow of nano-sized $\mathrm{Ca}_{2} \mathrm{Si}_{5} \mathrm{~N}_{8}$ : Eu, Tm particles which were excited just before injection [26]. Although the emission spectrum of $\mathrm{Ca}_{2} \mathrm{Si}_{5} \mathrm{~N}_{8}: \mathrm{Eu}, \mathrm{Tm}$ is at the edge of the tissue transparency window, imaging could still be performed. A top-down approach was used to obtain nano-sized particles, involving pulsed laser ablation or wet grinding, followed by size selection [26]. The rather complex synthesis conditions for the $\mathrm{M}_{2} \mathrm{Si}_{5} \mathrm{~N}_{8}$ : Eu do not easily allow a bottom-up synthesis method to obtain nano-sized particles with a priori specified size distribution.

The choice of surface functionalization (for instance with PEG (polyethylene glycol)) was shown to improve the distribution and keep the particles in the blood stream [26]. It also allows to tune the target specificity. Although $\mathrm{Ca}_{2} \mathrm{Si}_{5} \mathrm{~N}_{8}$ : Eu, Tm has the advantage that it can be recharged by irradiation with visible light after injection [31], the afterglow intensity is at the moment not sufficiently high to allow monitoring for extended periods, in contrast to recently reported $\mathrm{Cr}^{3+}$ persistent phosphors, which in addition have a more suited emission spectrum [15]. 
For $\mathrm{Sr}_{2} \mathrm{Si}_{5} \mathrm{~N}_{8}: \mathrm{Eu}$, Teng et al. reported the persistent luminescence afterglow time to be $150 \mathrm{~s}$, extending to 600s upon co-doping with $\mathrm{Tm}^{3+}$ [33], which is slightly longer than results described in [27]. Unfortunately, the traps relevant for the afterglow cannot be filled upon excitation with visible light (i.e. by excitation into the lowest $5 d$ excited states of divalent europium) [31], hampering several applications. Wang et al. reported persistent luminescence in $\mathrm{SrCaSi}_{5} \mathrm{~N}_{8}: E u, T m$, having a broad emission (FWHM of $120 \mathrm{~nm}$ ) peaking at $647 \mathrm{~nm}$, similar to the steady state photoluminescence [34]. The peak wavelength of the solid solution is red-shifted compared to the compounds $\mathrm{Sr}_{2} \mathrm{Si}_{5} \mathrm{~N}_{8}: \mathrm{Eu}$ and $\mathrm{Ca}_{2} \mathrm{Si}_{5} \mathrm{~N}_{8}: \mathrm{Eu}$, as reported earlier by Li et al. [54]. The traps in $\mathrm{SrCaSi}_{5} \mathrm{~N}_{8}: \mathrm{Eu}, \mathrm{Tm}$ can also be emptied with infrared stimulation (at $980 \mathrm{~nm}$ ), with fast response when switching the infrared excitation on and off [34].

Finally, $\mathrm{Ba}_{2} \mathrm{Si}_{5} \mathrm{~N}_{8}$ :Eu can show an afterglow for about 400 s, peaking at $585 \mathrm{~nm}$ [27]. Hoppe et al. already reported its persistent luminescence in 2000 and found an optimum composition of $\mathrm{Ba}_{1.89} \mathrm{Eu}_{0.11} \mathrm{Si}_{5} \mathrm{~N}_{8}$ [35]. Addition of Dy, Nd, Sm or Tm only shortens the afterglow duration. In the case of doping with $\mathrm{Tm}^{3+}$, the thermoluminescence glow peak shifts to lower temperature [27]. The trap filling process shows an interesting dependence on the both the temperature during the excitation and on the wavelength of the (monochromatic) excitation light (Fig. 1). When exciting $\mathrm{Ba}_{2} \mathrm{Si}_{5} \mathrm{~N}_{8}: \mathrm{Eu}$ with ultraviolet light at $285 \mathrm{~nm}$, the thermoluminescence glow peaks shift to higher temperature for higher excitation temperature. This is compatible with the presence of a trap distribution or multiple overlapping traps, rather than a single discrete trap [21]. At higher excitation temperature, the shallower traps are continuously being emptied and a shift of the TL glow curves to higher temperature is observed. This does however not result in significantly more (deep) traps being filled. For excitation at $420 \mathrm{~nm}$, into the lowest excited $5 \mathrm{~d}$ state of $\mathrm{Eu}^{2+}$, considerably more traps are filled at higher excitation temperature. This suggests a thermally activated step for the filling of the traps in this phosphor [31], which limits the afterglow obtained under excitation with visible light at room temperature.

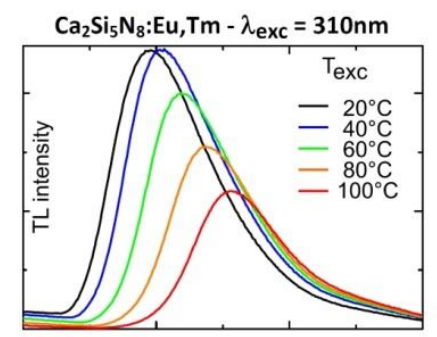

$\mathrm{Ca}_{2} \mathrm{Si}_{5} \mathrm{~N}_{8}: \mathrm{Eu}, \mathrm{Tm}-\lambda_{\text {exc }}=420 \mathrm{~nm}$

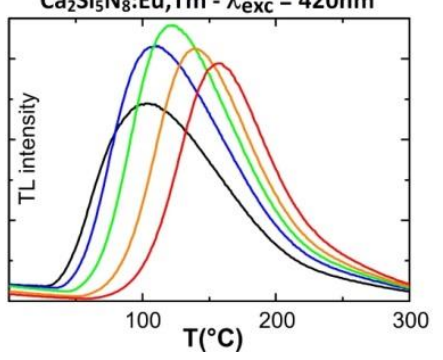

$\mathrm{Ba}_{2} \mathrm{Si}_{5} \mathrm{~N}_{8}: \mathrm{Eu}-\lambda_{\text {exc }}=285 \mathrm{~nm}$

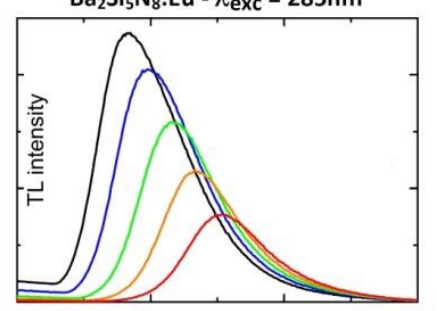

$\mathrm{Ba}_{2} \mathrm{Si}_{5} \mathrm{~N}_{8}: \mathrm{Eu}-\lambda_{\text {exc }}=420 \mathrm{~nm}$

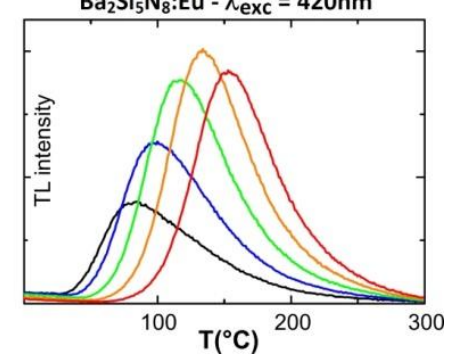

Fig. 1. Influence of the excitation wavelength $\left(\lambda_{\text {exc }}\right)$ and the temperature during excitation ( $\left.T_{\text {exc }}\right)$ on the thermoluminescence of $\mathrm{Ca}_{2} \mathrm{Si}_{5} \mathrm{~N}_{8}: \mathrm{Eu}$, Tm and $\mathrm{Ba}_{2} \mathrm{Si}_{5} \mathrm{~N}_{8}$ :Eu. After excitation the afterglow was recorded for $30 \mathrm{~s}$ (not shown, see [31] for more details). Then the sample was cooled to room temperature before starting the thermoluminescence measurement. Figure adapted from [31]. Permission requested. 
For $\mathrm{Ca}_{2} \mathrm{Si}_{5} \mathrm{~N}_{8}: \mathrm{Eu}, \mathrm{Tm}$ discussed above, there is only a limited improvement in trap filling at elevated excitation temperature, consistent with the observation that traps can easily be filled at room temperature upon low energy excitation [27, 28]. Li et al. obtained similar results for the afterglow intensity upon variation of the temperature during the excitation [29]. Based on this type of experiments, it was concluded that the ability to induce persistent luminescence apparently follows the thermal quenching behaviour. A lower thermal quenching temperature would correspond to a smaller distance between the lowest excited $5 \mathrm{~d}$ state and the host's conduction band, facilitating charge trapping [31]. It was shown that this suggestion does not hold for the $\mathrm{MSi}_{2} \mathrm{O}_{2} \mathrm{~N}_{2}$ :Eu phosphors, raising questions on the exact role of the conduction band levels on the trapping process [37]. Lastusaari et al. recently reported on the valence state of the europium ion in several oxide-based persistent phosphors $\left(\mathrm{SrAl}_{2} \mathrm{O}_{4}, \mathrm{Sr}_{2} \mathrm{MgSi}_{2} \mathrm{O}_{7}, \mathrm{Ba}_{2} \mathrm{MgSi}_{2} \mathrm{O}_{7}\right)$ [55]. For all materials, both divalent and trivalent europium ions were found, similar to other reports on $\mathrm{SrAl}_{2} \mathrm{O}_{4}: \mathrm{Eu}$, Dy and $\mathrm{CaAl}_{2} \mathrm{O}_{4}: \mathrm{Eu}$ [20, 56]. Figure 2 shows that also for $\mathrm{Ca}_{2} \mathrm{Si}_{5} \mathrm{~N}_{8}: \mathrm{Eu}[1 \%]$ about $10 \%$ of the europium ions is in the trivalent state, which increase to about $18 \%$ for $\mathrm{Ca}_{2} \mathrm{Si}_{5} \mathrm{~N}_{8}: \mathrm{Eu}[1 \%], \mathrm{Tm}[1 \%]$. Based on sequential measurements, it was verified that the presence of $\mathrm{Eu}^{3+}$ in this case is not related to sample degradation or oxidation caused by the $x$-ray irradiation, but presumably originates from the synthesis conditions. The coexistence of both valence states of europium in the same material is not uncommon [57], and does not necessarily have to be reflected in the emission spectrum [56]. More detailed studies are required to evaluate the relation between the trapping/detrapping processes and the oxidation/reduction of the europium ions [20]. While the presence of different valence states for the lanthanide ions in persistent phosphors is not uncommon, the possible dynamics are still under debate $[58,59]$.

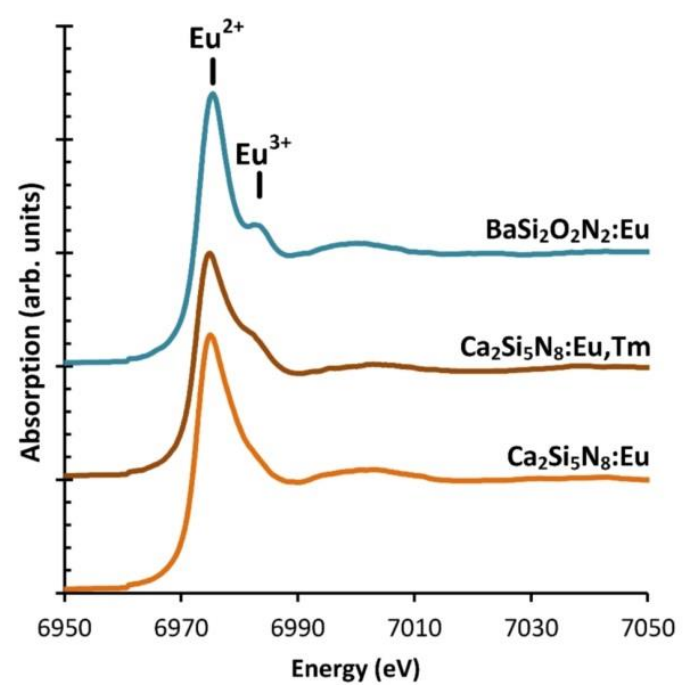

Fig. 2. XANES (x-ray absorption near edge spectroscopy) on the $\mathrm{L}_{\| 1}$ edge of Eu for $\mathrm{Ca}_{2} \mathrm{Si}_{5} \mathrm{~N}_{8}: \mathrm{Eu}, \mathrm{Ca}_{2} \mathrm{Si}_{5} \mathrm{~N}_{8}: \mathrm{Eu}, \mathrm{Tm}$ and $\mathrm{BaSi}_{2} \mathrm{O}_{2} \mathrm{~N}_{2}: \mathrm{Eu}$. Spectra were vertically displaced to improve readability. The positions for the white lines of $\mathrm{Eu}^{2+}$ and $\mathrm{Eu}^{3+}$ are indicated.

An important asset of the nitrido-silicates is their high chemical stability, which also translates to their luminescent properties. As an example, figure 3 shows the influence of water on maintenance of the persistent luminescence of $\mathrm{Ca}_{2} \mathrm{Si}_{5} \mathrm{~N}_{8}: \mathrm{Eu}, \mathrm{Tm}$ compared to some other common and commercially available persistent phosphors. After storage in (distilled) water for two years at room temperature, the intensity of the persistent luminescence has decreased by only $2 \%$ compared to that of a sample stored in a sealed container. This test was chosen to resemble actual (outdoor) 
usage conditions, rather than an accelerated test at high temperature and high humidity. For the other persistent phosphors, the stability is much lower. For example, the afterglow intensity of $\mathrm{SrAl}_{2} \mathrm{O}_{4}: \mathrm{Eu}$,Dy has decreased over $50 \%$ after storage in water for two years.

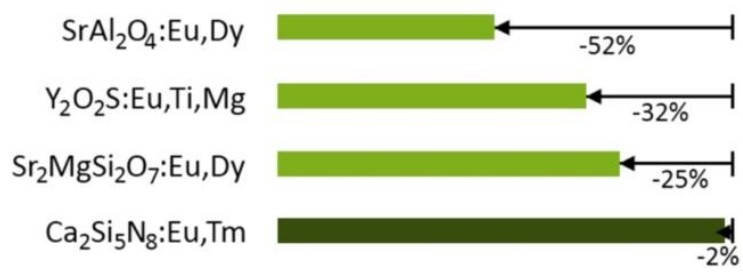

Fig. 3. Decrease of the persistent luminescence intensity after two years storage in (distilled) water for $\mathrm{Ca}_{2} \mathrm{Si}_{5} \mathrm{~N}_{8}: \mathrm{Eu}$, Tm and selected common persistent phosphors, compared to samples stored in a sealed container.

Tang et al. reported yellowish persistent luminescence in graphitic $\mathrm{C}_{3} \mathrm{~N}_{4}\left(\mathrm{~g}-\mathrm{C}_{3} \mathrm{~N}_{4}\right)$ [36]. This chemically stable compound can be made through facile synthesis methods at relatively low temperature. The steady state photoluminescence can be tuned from blue to yellow depending on the morphology and the material synthesis conditions [60]. The persistent luminescence is however red-shifted compared to the steady state luminescence, peaking at 553nm [36]. Tang et al. demonstrated the use of this phosphor to detect thiols in biological fluids. This was shown by first quenching the persistent luminescence of $\mathrm{g}-\mathrm{C}_{3} \mathrm{~N}_{4}$ nanopowders by adsorbing $\mathrm{Ag}^{+}$ions at the surface. In the presence of thiols, the silver ions desorbed from the surface, due to the great affinity of thiols to $\mathrm{Ag}^{+}$, hence leading to a recovery of the persistent luminescence [36]. Although the optical signal appeared weak, the absence of an excitation or probe light source avoids disturbance by autofluorescence of other compounds or tissue in the sample volume. The same advantage is exploited in the case of persistent luminescent nanoparticles for in vivo imaging.

\section{Overview of oxynitride phosphors}

Similar to the case of the nitride phosphors, the search for efficient oxynitride phosphors has been driven by the need for efficient colour conversion materials in LEDs [44, 45]. It was demonstrated ten years ago that $\mathrm{SrSi}_{2} \mathrm{O}_{2} \mathrm{~N}_{2}: \mathrm{Eu}$ is an interesting green conversion phosphor [61]. Luminescence properties of the $\mathrm{MSi}_{2} \mathrm{O}_{2} \mathrm{~N}_{2}$ :Eu compounds $(\mathrm{M}=\mathrm{Ca}, \mathrm{Sr}, \mathrm{Ba}$ ) were investigated in detail by Bachmann et al. [62]. Among these three compounds, $\mathrm{SrSi}_{2} \mathrm{O}_{2} \mathrm{~N}_{2}$ :Eu shows the highest quantum efficiency and thermal quenching temperature. Colour tuning can be achieved in a certain range by partial substitution of strontium by barium [62]. Synthesis is typically performed under reducing atmosphere at elevated temperature (typically $1400^{\circ} \mathrm{C}$ ), using $\mathrm{MCO}_{3}$ (or $\mathrm{M}_{2} \mathrm{SiO}_{4}$ ) and $\mathrm{Si}_{3} \mathrm{~N}_{4}$. $\mathrm{CaSi}_{2} \mathrm{O}_{2} \mathrm{~N}_{2}: \mathrm{Eu}$ [37], $\mathrm{SrSi}_{2} \mathrm{O}_{2} \mathrm{~N}_{2}: \mathrm{Eu}[37,38]$ and $\mathrm{BaSi}_{2} \mathrm{O}_{2} \mathrm{~N}_{2}: \mathrm{Eu}[37,40,41]$ show persistent luminescence as well, with an afterglow spectrum that is similar to the steady state photoluminescence spectrum.

Botterman et al. compared these three $\mathrm{MSi}_{2} \mathrm{O}_{2} \mathrm{~N}_{2}: \mathrm{Eu}$ compounds under identical excitation conditions [37]. After excitation with 1000lux unfiltered Xe light (containing both visible and UV light), the afterglow duration was $400 \mathrm{~s}(\mathrm{Ca}), 6000 \mathrm{~s}(\mathrm{Sr})$ and $2800 \mathrm{~s}(\mathrm{Ba})$, when taking $0.32 \mathrm{mcd} / \mathrm{m}^{2}$ as the threshold value [37, 38]. Although $\mathrm{SrSi}_{2} \mathrm{O}_{2} \mathrm{~N}_{2}$ :Eu and $\mathrm{BaSi}_{2} \mathrm{O}_{2} \mathrm{~N}_{2}$ :Eu start with similar afterglow intensity, the decay in the latter compound is somewhat faster, which could be related to a slightly smaller trap depth for $\mathrm{BaSi}_{2} \mathrm{O}_{2} \mathrm{~N}_{2}$ :Eu as derived from thermoluminescence measurements (Fig. 4). When changing the excitation light to the visible range (at $425 \mathrm{~nm}$ ), the afterglow behaviour is considerably different for the three compounds [37]. Not only is the afterglow negligible in 
$\mathrm{CaSi}_{2} \mathrm{O}_{2} \mathrm{~N}_{2}: \mathrm{Eu}$, also for $\mathrm{SrSi}_{2} \mathrm{O}_{2} \mathrm{~N}_{2}: \mathrm{Eu}$ it is hardly possible to fill the traps with visible light, leading to an afterglow time of only a few seconds. For $\mathrm{BaSi}_{2} \mathrm{O}_{2} \mathrm{~N}_{2}$ :Eu however, a reasonably high trap filling efficiency is obtained upon excitation with visible light.
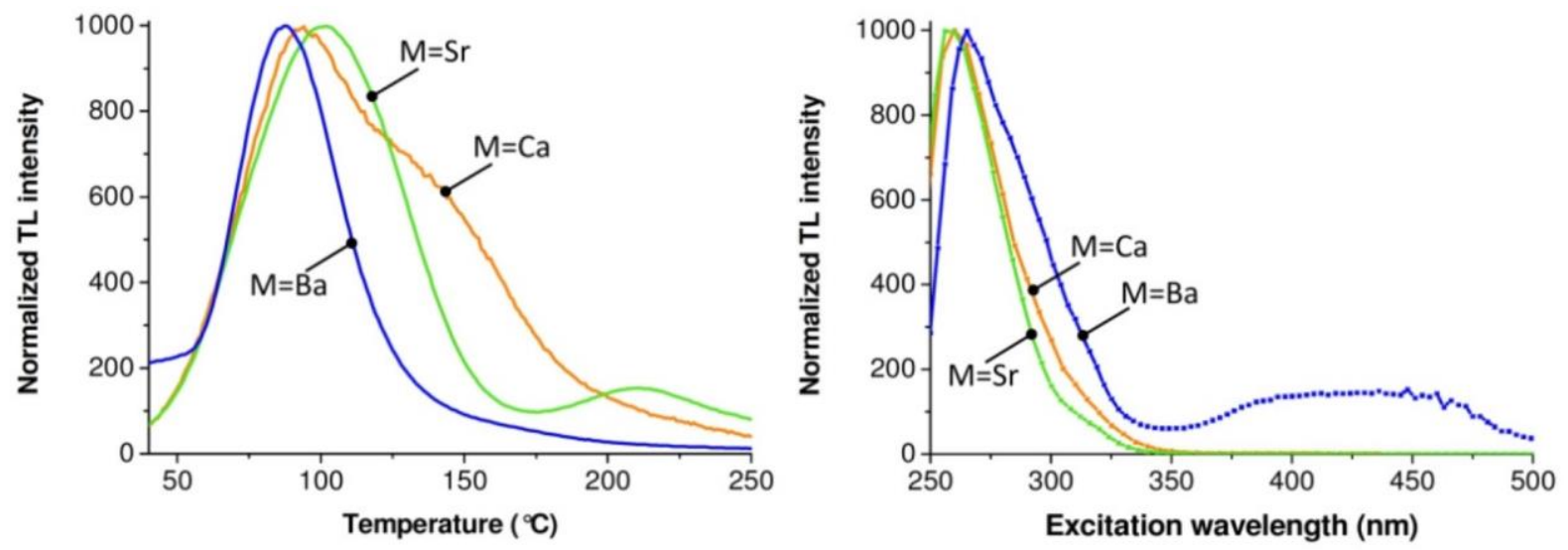

Fig. 4. (left) TL glow curves for $\mathrm{MSi}_{2} \mathrm{O}_{2} \mathrm{~N}_{2}$ :Eu (heating rate of $5 \mathrm{~K} / \mathrm{s}$ ). (right) Trap filling spectra for $\mathrm{MSi}_{2} \mathrm{O}_{2} \mathrm{~N}_{2}: \mathrm{Eu}$, extracted from TL excitation spectroscopy. Figure adapted from [37]. Permission requested.

By means of thermoluminescence excitation spectroscopy it was confirmed that no traps can be filled with wavelengths longer than $350 \mathrm{~nm}$ in $\mathrm{CaSi}_{2} \mathrm{O}_{2} \mathrm{~N}_{2}$ : $\mathrm{Eu}$ and $\mathrm{SrSi}_{2} \mathrm{O}_{2} \mathrm{~N}_{2}$ : $\mathrm{Eu}$ (Fig. 4) [37]. This means that for use in phosphor-converted LEDs no afterglow will be visible when switching off the blue pumping LED. Based on the shape of the trap filling spectra (Fig. 4) it appears that the creation (and subsequent trapping) of charges via excitation in the lowest $5 \mathrm{~d}$ state(s) of $\mathrm{Eu}^{2+}$ is impossible in these compounds. For $\mathrm{BaSi}_{2} \mathrm{O}_{2} \mathrm{~N}_{2}$ :Eu this is not the case, as the phosphor can easily be excited with visible light up to $500 \mathrm{~nm}$. Similar observations on $\mathrm{SrSi}_{2} \mathrm{O}_{2} \mathrm{~N}_{2}$ :Eu and $\mathrm{BaSi}_{2} \mathrm{O}_{2} \mathrm{~N}_{2}:$ Eu were reported by Zhang et al [38] and Qin et al [40].

The thermoluminescence glow peaks of the $\mathrm{MSi}_{2} \mathrm{O}_{2} \mathrm{~N}_{2}$ : Eu phosphors are not straightforwardly interpretable, as they contain multiple, often overlapping peaks [37, 38, 40, 42]. For $\mathrm{BaSi}_{2} \mathrm{O}_{2} \mathrm{~N}_{2}: \mathrm{Eu}$, the main TL glow peak lies at relatively low temperature (335K for a heating rate of $1.4 \mathrm{~K} / \mathrm{s}$ [41], 360K at $5 \mathrm{~K} / \mathrm{s}$ [37]), along with a less prominent deep trap at around $420 \mathrm{~K}[37,41]$. Surprisingly, for these compounds there are no reports available on co-dopants which could alter the afterglow intensity or duration, as is commonly the case for the aluminates and the silicates [7]. We therefore investigated the influence of rare earth co-dopants on the integrated afterglow intensity in $\mathrm{BaSi}_{2} \mathrm{O}_{2} \mathrm{~N}_{2}$ : $\mathrm{Eu}$ (Fig. 5).

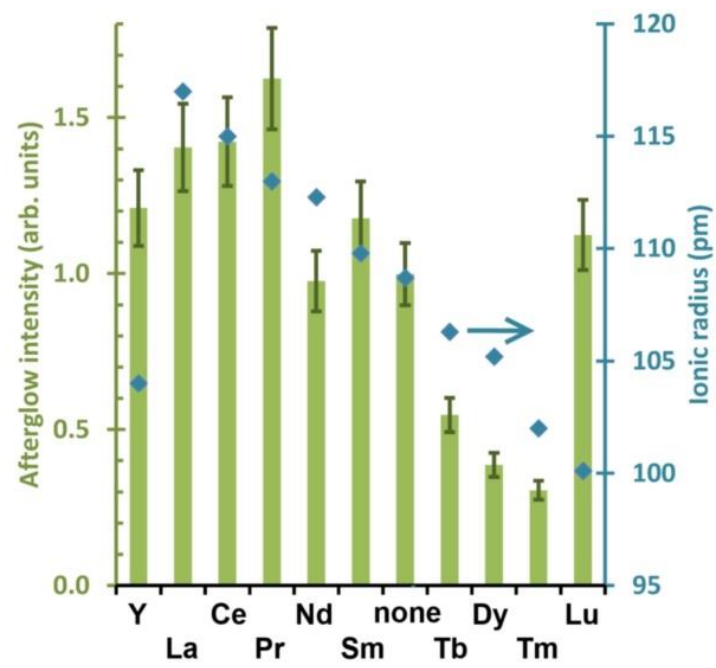


Fig. 5. Influence of co-dopants on the afterglow intensity of $\mathrm{BaSi}_{2} \mathrm{O}_{2} \mathrm{~N}_{2}$ :Eu normalized to the intensity for $\mathrm{BaSi}_{2} \mathrm{O}_{2} \mathrm{~N}_{2}$ :Eu without co-dopants ('none'). The diamonds show the ionic radius (in octahedral surrounding).

None of the evaluated co-dopants can significantly increase the afterglow intensity, in contrast to the case of adding Dy to $\mathrm{SrAl}_{2} \mathrm{O}_{4}: \mathrm{Eu}$ or $\mathrm{Tm}$ to $\mathrm{Ca}_{2} \mathrm{Si}_{5} \mathrm{~N}_{8}$ :Eu. The highest increase, of about $50 \%$, is found upon addition of $\mathrm{Pr}^{3+}$, which is not often found to enhance the afterglow. Co-doping with $\mathrm{Tm}$ considerably reduces the afterglow intensity by about $70 \%$. Although the TL glow curve shifted by about $5^{\circ} \mathrm{C}$ to lower temperature upon addition of $\mathrm{Tm}^{3+}$ (not shown), the main effect appears to be the reduction of the number of traps. There seems to be some correlation between the afterglow intensity and the ionic radius of the co-dopant (Fig. 5). As the $\mathrm{BaSi}_{2} \mathrm{O}_{2} \mathrm{~N}_{2}$ host can form domains with different stacking order for the silicate layers $[39,63,64]$, it is not unlikely that the size of the codopants incorporated into the material can influence the crystallographic structure. As a consequence, the defect structure can change, affecting the number and depth of traps. This assumption is however not more than a hypothesis, as co-doping with $\mathrm{Y}^{3+}$ and $\mathrm{Lu}^{3+}$ does not follow the observed trend. A more detailed study, merging luminescence and structural characterization, is needed to explain the observations.

In terms of the trapping mechanism, oxygen and nitrogen related defects (vacancies or substitutions) were suggested as electron traps in $\mathrm{BaSi}_{2} \mathrm{O}_{2} \mathrm{~N}_{2}[38,41]$. Cation vacancies were suggested as hole traps $[38,40]$, although it is not clear why hole trapping would occur, if the same mechanism as in Eudoped aluminates $\left(\mathrm{Eu}^{2+}->\mathrm{Eu}^{3+}+\right.$ trapped electron) is at play [20]. X-ray absorption measurements indicate the simultaneous presence of $\mathrm{Eu}^{2+}$ and $\mathrm{Eu}^{3+}$ in $\mathrm{BaSi}_{2} \mathrm{O}_{2} \mathrm{~N}_{2}$ : $\mathrm{Eu}$ (Fig. 2). However, little is currently known about the defects involved in these oxynitride phosphors and more dedicated research is needed. For $\mathrm{BaSi}_{2} \mathrm{O}_{2} \mathrm{~N}_{2}: \mathrm{Eu}$, a thermally assisted tunneling process was proposed as well [41].

From a practical point of view, $\mathrm{BaSi}_{2} \mathrm{O}_{2} \mathrm{~N}_{2}$ :Eu turns out to be the best candidate in this material class, due to the possibility to excite it with visible light. In addition, it also shows a strong mechanoluminescence (ML, also known as elasticoluminescence) [39]. Upon application of pressure or friction, light is emitted if the material was previously exposed to (short wavelength) light having the ability to fill traps $[65,66]$. This process is non-destructive, and can be repeated by illuminating the material with blue or UV light after the mechanical stimulus. The occurrence of mechanoluminescence in $\mathrm{BaSi}_{2} \mathrm{O}_{2} \mathrm{~N}_{2}$ : Eu is related to its specific crystallographic structure and to the presence of many defects, as witnessed from the long afterglow in this compound [39]. Compared to the steady state photoluminescence spectrum, the ML emission spectrum is shifted by about $4 \mathrm{~nm}$ to longer wavelengths. A similar shift is observed in the afterglow spectrum without the application of pressure, showing the close connection between both phenomena. Although $\mathrm{BaSi}_{2} \mathrm{O}_{2} \mathrm{~N}_{2}$ : Eu shows a fast $\mathrm{ML}$ response upon applying the mechanical stimulus, the phosphor also emits light after the removal of the stimulus, with a decay behaviour similar to the 'normal' afterglow behaviour. This could be related to the release of electrons from deep traps during the mechanical stimulus, and (partial) trapping at the shallower traps responsible for the afterglow emission [39].

Although the largest number of reports on persistent luminescence in oxynitride hosts is related to the $\mathrm{MSi}_{2} \mathrm{O}_{2} \mathrm{~N}_{2}$ composition, many more oxynitride compositions have been investigated as hosts for rare earth luminescence, including the oxonitridosilicates, oxonitridoaluminosilicates and sialons [45]. Somewhat surprisingly, there are almost no reports on the occurrence of persistent luminescence in these compounds with composition other than $\mathrm{MSi}_{2} \mathrm{O}_{2} \mathrm{~N}_{2}$. 
Zhang et al. prepared $\mathrm{BaAlSi}_{5} \mathrm{~N}_{7} \mathrm{O}_{2}: \mathrm{Eu}$, showing persistent luminescence characterized by a cyan colour, visible for about 40 minutes [42]. This phosphor shows a broad emission spectrum, with a remarkably large stokes shift. It was not reported what wavelengths are required to induce the persistent luminescence. The excitation spectrum however shows a very low excitation intensity beyond $375 \mathrm{~nm}$ [42].

Finally, Liu et al. reported BCNO as a persistent phosphor [43, 67], which is structurally considerably different from the previously mentioned $\mathrm{Eu}^{2+}$-based oxynitrides, as this phosphor contains no rare earth or transition metal impurities. It is amorphous and can be regarded as C-doped BNO [43]. Several photoluminescence bands were observed ( $\sim 335 \mathrm{~nm}, 410 \mathrm{~nm}$ and $520 \mathrm{~nm})$, depending on the exact composition. Only the $\sim 520 \mathrm{~nm}$ emission band (FWHM of about $90 \mathrm{~nm}$ ) was obtained in the afterglow, leading to a yellowish-green colour.

No thermoluminescence glow curves were reported on this BCNO phosphor. On the basis of the afterglow following a $\mathrm{t}^{-0.93}$ behaviour, a tunneling mechanism was proposed for the de-trapping [43]. The traps were assumed to consist of nitrogen vacancies, stabilized by the $C$ impurities. By means of electron paramagnetic resonance (EPR), a signal at $\mathrm{g}=2.0$ was found to decrease synchronously with the afterglow decay $[43,67]$. The excitation spectra for the steady state photoluminescence and the persistent luminescence were remarkably similar, allowing to obtain persistent luminescence upon charging with visible light up to 500nm [43].

\section{Conclusions and outlook.}

Since the discovery of $\mathrm{SrAl}_{2} \mathrm{O}_{4}: \mathrm{Eu}$, Dy as an efficient persistent phosphor, now twenty years ago, many new phosphor compositions have been proposed. Most of them are however not on par with $\mathrm{SrAl}_{2} \mathrm{O}_{4}$ :Eu,Dy in terms of excitability, afterglow intensity, afterglow duration and chemical stability. Only recently, europium-doped nitride and oxynitride persistent phosphors emerged, holding the promise of afterglow emission in the long wavelength part of the visible spectrum, combined with excitability by blue light and chemical stability. The two most important compounds from an application point of view appear to be $\mathrm{Ca}_{2} \mathrm{Si}_{5} \mathrm{~N}_{8}: \mathrm{Eu}$, Tm and $\mathrm{BaSi}_{2} \mathrm{O}_{2} \mathrm{~N}_{2}$ : Eu. The former is an orange-red emitting persistent phosphor, with reasonably strong afterglow intensity, for which the use of thulium as co-dopant is crucial. It was also successfully tested as nano-sized phosphor for in vivo bioimaging. The latter compound, emitting bluish-green light, shows a strong mechanoluminescence signal which could be useful for pressure sensing applications. In addition to these more traditional phosphors, $\mathrm{BCNO}$ and graphitic- $\mathrm{C}_{3} \mathrm{~N}_{4}$ might open up a novel direction for persistent luminescence and its use in bio-applications.

It is clear that the class of rare-earth doped (oxy)nitrides has not fully been explored yet in view of their use as persistent phosphor, as the main focus in phosphor research lies in their potential use as LED phosphor, where long afterglows are disadvantageous. Phosphors which turn out to be less suitable for LED applications, for instance due to a lower thermal quenching temperature, might be very useful for persistent luminescence upon appropriate co-doping or variation of the synthesis conditions. Although the chemical stability is excellent for most of the (oxy)nitride phosphors, their often complex synthesis methods are a disadvantage, especially if larger phosphor quantities are required (e.g. in the case of emergency signage) or if specific phosphor size distributions are needed (e.g. for use in vivo imaging). In any case, it seems that further compositional optimization of the already reported (oxy)nitride materials is still needed to considerably increase their charge storage 
capacity. Finally, more research should be directed towards understanding the mechanism of persistent luminescence in (oxy)nitride phosphors, although this statement also holds for even more established phosphors, such as the aluminates and silicates.

In that respect, the prime dopant element in (oxy)nitride persistent phosphors is still divalent europium, inspired by investigations in the context of LED applications where high thermal quenching temperatures are needed. Exploring the use of $\mathrm{Yb}^{2+}$ as dopant element might also turn out to be fruitful [68], given the some closer proximity of the $\mathrm{Yb}^{2+} 5 \mathrm{~d}$ state to the bottom of the conduction band (as compared to $\mathrm{Eu}^{2+}$ ), which could be favourable for the electron trapping and detrapping processes.

\section{Acknowledgments.}

JB and KK acknowledge the Special Research Fund at Ghent University (BOF-UGent) for a research grant. The authors are grateful to staff at the BM26a beam line for assistance during the $x$-ray absorption measurements at the ESRF (application $n^{\circ} 26-01-899$ ).

\section{References.}

[1] H.F. Brito, J. Holsa, T. Laamanen, M. Lastusaari, M. Malkamaki, L.C.V. Rodrigues, Opt. Mater. Express, 2 (2012), pp. 371-381.

[2] P.F. Smet, D. Poelman, M.P. Hehlen, Opt. Mater. Express, 2 (2012), pp. 452-454.

[3] M. Lastusaari, T. Laamanen, M. Malkamaki, K.O. Eskola, A. Kotlov, S. Carlson, E. Welter, H.F. Brito, M. Bettinelli, H. Jungner, J. Holsa, Eur. J. Mineral., 24 (2012), pp. 885-890.

[4] Y. Murayama, N. Takeuchi, Y. Aoki, T. Matsuzawa, Phosphorescent phosphor (EP0622440), 1994.

[5] T. Matsuzawa, Y. Aoki, N. Takeuchi, Y. Murayama, J. Electrochem. Soc., 143 (1996), pp. 26702673.

[6] K. Van den Eeckhout, D. Poelman, P.F. Smet, Materials, 6 (2013), pp. 2789-2818.

[7] K. Van den Eeckhout, P.F. Smet, D. Poelman, Materials, 3 (2010), pp. 2536-2566.

[8] P.F. Smet, N. Avci, K. Van den Eeckhout, D. Poelman, Opt. Mater. Express, 2 (2012), pp. 13061313.

[9] J. Ueda, T. Shinoda, S. Tanabe, Opt. Mater. Express, 3 (2013), pp. 787-793.

[10] Y.H. Lin, Z.L. Tang, Z.T. Zhang, X.X. Wang, J.Y. Zhang, Journal of Materials Science Letters, 20 (2001), pp. 1505-1506.

[11] A. Nag, T.R.N. Kutty, Journal of Alloys and Compounds, 354 (2003), pp. 221-231.

[12] Y.H. Lin, Z.L. Tang, Z.T. Zhang, Mater. Lett., 51 (2001), pp. 14-18.

[13] A. Bessiere, A. Lecointre, R.A. Benhamou, E. Suard, G. Wallez, B. Viana, J. Mater. Chem. C, 1 (2013), pp. 1252-1259.

[14] A. Bessiere, S.K. Sharma, N. Basavaraju, K.R. Priolkar, L. Binet, B. Viana, A.J.J. Bos, T. Maldiney, C. Richard, D. Scherman, D. Gourier, Chemistry of Materials, 26 (2014), pp. 1365-1373.

[15] T. Maldiney, A. Bessiere, J. Seguin, E. Teston, S.K. Sharma, B. Viana, A.J.J. Bos, P. Dorenbos, M. Bessodes, D. Gourier, D. Scherman, C. Richard, Nat. Mater., 13 (2014), pp. 418-426.

[16] Z.W. Pan, Y.Y. Lu, F. Liu, Nat. Mater., 11 (2012), pp. 58-63.

[17] A.J.J. Bos, Radiat. Meas., 41 (2006), pp. S45-S56.

[18] P. Dorenbos, A.J.J. Bos, N.R.J. Poolton, F.T. You, J. Lumines., 133 (2013), pp. 45-50.

[19] A. Vedda, M. Nikl, M. Fasoli, E. Mihokova, J. Pejchal, M. Dusek, G. Ren, C.R. Stanek, K.J.

McClellan, D.D. Byler, Phys. Rev. B, 78 (2008), p. 195123.

[20] K. Korthout, K. Van den Eeckhout, J. Botterman, S. Nikitenko, D. Poelman, P.F. Smet, Phys. Rev. B, 84 (2011), p. 085140.

[21] K. Van den Eeckhout, A.J.J. Bos, D. Poelman, P.F. Smet, Phys. Rev. B, 87 (2013), p. 045126.

[22] D. Poelman, N. Avci, P.F. Smet, Opt. Express, 17 (2009), pp. 358-364. 
[23] D. Poelman, P.F. Smet, Opt. Express, 18 (2010), pp. 26293-26299.

[24] F. Liu, W.Z. Yan, Y.J. Chuang, Z.P. Zhen, J. Xie, Z.W. Pan, Sci Rep, 3 (2013), p. 1554.

[25] Q.L. de Chermont, C. Chaneac, J. Seguin, F. Pelle, S. Maitrejean, J.P. Jolivet, D. Gourier, M. Bessodes, D. Scherman, Proc. Natl. Acad. Sci. U. S. A., 104 (2007), pp. 9266-9271.

[26] T. Maldiney, G. Sraiki, B. Viana, D. Gourier, C. Richard, D. Scherman, M. Bessodes, K. Van den Eeckhout, D. Poelman, P.F. Smet, Opt. Mater. Express, 2 (2012), pp. 261-268.

[27] K. Van den Eeckhout, P.F. Smet, D. Poelman, Materials, 4 (2011), pp. 980-990.

[28] B. Lei, K. Machida, T. Horikawa, H. Hanzawa, N. Kijima, Y. Shimomura, H. Yamamoto, J.

Electrochem. Soc., 157 (2010), pp. J196-J201.

[29] J.F. Li, B.F. Lei, J.L. Qin, Y.L. Liu, X.T. Liu, J. Am. Ceram. Soc., 96 (2013), pp. 873-878.

[30] Y. Miyamoto, H. Kato, Y. Honna, H. Yamamoto, K. Ohmi, J. Electrochem. Soc., 156 (2009), pp.

J235-J241.

[31] P.F. Smet, K. Van den Eeckhout, A.J.J. Bos, E. van der Kolk, P. Dorenbos, J. Lumines., 132 (2012), pp. 682-689.

[32] K. Van den Eeckhout, P.F. Smet, D. Poelman, J. Lumines., 129 (2009), pp. 1140-1143.

[33] X.M. Teng, Y.H. Liu, Y.Z. Liu, Y.S. Hu, H.Q. He, W.D. Zhuang, J. Lumines., 130 (2010), pp. 851-854.

[34] J. Wang, H. Zhang, B. Lei, H. Dong, H. Zhang, Y. Liu, N. Lai, Y. Fang, Z. Chen, Optical Materials (in press: http://dx.doi.org/10.1016/j.optmat.2014.04.048 ).

[35] H.A. Hoppe, H. Lutz, P. Morys, W. Schnick, A. Seilmeier, J. Phys. Chem. Solids, 61 (2000), pp. 2001-2006.

[36] Y.R. Tang, H.J. Song, Y.Y. Su, Y. Lv, Anal. Chem., 85 (2013), pp. 11876-11884.

[37] J. Botterman, K. Van den Eeckhout, A.J.J. Bos, P. Dorenbos, P.F. Smet, Opt. Mater. Express, 2 (2012), pp. 341-349.

[38] H.R. Zhang, B.F. Lei, J.L. Qin, J.F. Li, Y.L. Liu, X.T. Liu, M.T. Zheng, Y. Xiao, H.W. Dong, J. Am. Ceram. Soc., 96 (2013), pp. 1810-1814.

[39] J. Botterman, K. Van den Eeckhout, I. De Baere, D. Poelman, P.F. Smet, Acta Mater., 60 (2012), pp. 5494-5500.

[40] J.L. Qin, H.R. Zhang, B.F. Lei, C.F. Hu, J.F. Li, Y.L. Liu, J.X. Meng, J. Wang, M.T. Zheng, Y. Xiao, J. Am. Ceram. Soc., 96 (2013), pp. 3149-3154.

[41] M.Y. Wang, X. Zhang, Z.D. Hao, X.G. Ren, Y.S. Luo, H.F. Zhao, X.J. Wang, J.H. Zhang, J.

Electrochem. Soc., 157 (2010), pp. H178-H181.

[42] H.R. Zhang, M.T. Zheng, B.F. Lei, Y. Xiao, H.W. Dong, Y.L. Liu, X.T. Liu, J.J. Deng, J.W. Deng, Z.L. Huang, ECS Solid State Lett., 2 (2013), pp. R16-R18.

[43] X.F. Liu, Y.B. Qiao, G.P. Dong, S. Ye, B. Zhu, Y.X. Zhuang, J.R. Qiu, J. Electrochem. Soc., 156 (2009), pp. P81-P84.

[44] R.J. Xie, H.T. Hintzen, J. Am. Ceram. Soc., 96 (2013), pp. 665-687.

[45] R.J. Xie, N. Hirosaki, Sci. Technol. Adv. Mater., 8 (2007), pp. 588-600.

[46] P.F. Smet, A.B. Parmentier, D. Poelman, J. Electrochem. Soc., 158 (2011), pp. R37-R54.

[47] P. Dorenbos, J. Lumines., 104 (2003), pp. 239-260.

[48] D. Poelman, J.E. Van Haecke, P.F. Smet, J. Mater. Sci.-Mater. Electron., 20 (2009), pp. 134-138.

[49] N. Avci, J. Musschoot, P.F. Smet, K. Korthout, A. Avci, C. Detavernier, D. Poelman, J. Electrochem. Soc., 156 (2009), pp. J333-J337.

[50] Y.Q. Li, J.E.J. van Steen, J.W.H. van Krevel, G. Botty, A.C.A. Delsing, F.J. DiSalvo, G. de With, H.T. Hintzen, Journal of Alloys and Compounds, 417 (2006), pp. 273-279.

[51] X.Q. Piao, T. Horikawa, H. Hanzawa, K. Machida, J. Electrochem. Soc., 153 (2006), pp. H232$\mathrm{H} 235$.

[52] K. Uheda, N. Hirosaki, Y. Yamamoto, A. Naito, T. Nakajima, H. Yamamoto, Electrochem. Solid State Lett., 9 (2006), pp. H22-H25.

[53] H. Watanabe, H. Wada, K. Seki, M. Itoua, N. Kijima, J. Electrochem. Soc., 155 (2008), pp. F31-F36. [54] Y.Q. Li, G. de With, H.T. Hintzen, Journal of Solid State Chemistry, 181 (2008), pp. 515-524.

[55] M. Lastusaari, H.F. Brito, S. Carlson, J. Holsa, T. Laamanen, L.C.V. Rodrigues, E. Welter, Phys. Scr., 89 (2014), p. 044004. 
[56] N. Avci, K. Korthout, M.A. Newton, P.F. Smet, D. Poelman, Opt. Mater. Express, 2 (2012), pp. 321-330.

[57] M. Peng, Z. Pei, G. Hong, Q. Su, Journal of Materials Chemistry, 13 (2003), pp. 1202-1205.

[58] J. Holsa, T. Laamanen, M. Lastusaari, M. Malkamaki, E. Welter, D.A. Zajac, Spectroc. Acta Pt. BAtom. Spectr., 65 (2010), pp. 301-305.

[59] L.C.V. Rodrigues, J. Holsa, J.M. Carvalho, C.C.S. Pedroso, M. Lastusaari, M. Felinto, S. Watanabe, H.F. Brito, Physica B, 439 (2014), pp. 67-71.

[60] Y.H. Zhang, Q.W. Pan, G.Q. Chai, M.R. Liang, G.P. Dong, Q.Y. Zhang, J.R. Qiu, Sci Rep, 3 (2013), p. 1943.

[61] R. Mueller-Mach, G. Mueller, M.R. Krames, H.A. Hoppe, F. Stadler, W. Schnick, T. Juestel, P. Schmidt, Phys. Status Solidi A-Appl. Mat., 202 (2005), pp. 1727-1732.

[62] V. Bachmann, C. Ronda, O. Oeckler, W. Schnick, A. Meijerink, Chemistry of Materials, 21 (2009), pp. 316-325.

[63] J.A. Kechele, O. Oeckler, F. Stadler, W. Schnick, Solid State Sci., 11 (2009), pp. 537-543.

[64] M. Seibald, T. Rosenthal, O. Oeckler, W. Schnick, Critical Reviews in Solid State and Materials Sciences, 39 (2014), pp. 215-229.

[65] B.P. Chandra, R.N. Baghel, A.K. Luka, T.R. Sanodiya, R.K. Kuraria, S.R. Kuraria, J. Lumines., 129 (2009), pp. 760-766.

[66] C.N. Xu, X.G. Zheng, M. Akiyama, K. Nonaka, T. Watanabe, Appl. Phys. Lett., 76 (2000), pp. $179-$ 181.

[67] X.F. Liu, S. Ye, G.P. Dong, Y.B. Qiao, J. Ruan, Y.X. Zhuang, Q. Zhang, G. Lin, D.P. Chen, J.R. Qiu, J. Phys. D-Appl. Phys., 42 (2009), p. 215409.

[68] H. Kanno, K. Noda, K. Matsui, Chemical Physics Letters, 580 (2013), pp. 103-107. 